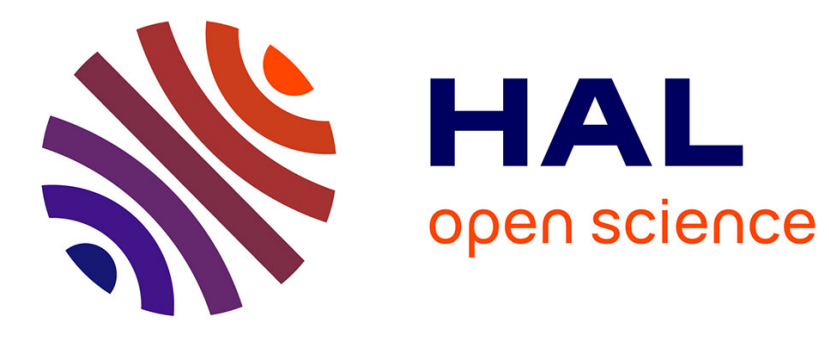

\title{
Runner-up patents: is monopoly inevitable?
}

Emeric Henry

\section{To cite this version:}

Emeric Henry. Runner-up patents: is monopoly inevitable?. Scandinavian Journal of Economics, 2010, 112 (2), pp.417-441. 10.1111/j.1467-9442.2010.01603.x . hal-01023778

\section{HAL Id: hal-01023778 \\ https://hal-sciencespo.archives-ouvertes.fr/hal-01023778}

Submitted on 15 Jul 2014

HAL is a multi-disciplinary open access archive for the deposit and dissemination of scientific research documents, whether they are published or not. The documents may come from teaching and research institutions in France or abroad, or from public or private research centers.
L'archive ouverte pluridisciplinaire HAL, est destinée au dépôt et à la diffusion de documents scientifiques de niveau recherche, publiés ou non, émanant des établissements d'enseignement et de recherche français ou étrangers, des laboratoires publics ou privés. 


\title{
Runner-up Patents: Is Monopoly Inevitable?
}

\author{
Emeric Henry* \\ Sciences Po, FR-75007 Paris, France \\ emeric.henry@sciences-po.fr
}

\begin{abstract}
Exclusive patents sacrifice product competition to provide firms incentives to innovate. We characterize an alternative mechanism whereby later inventors are allowed to share the patent if they discover within a certain time period of the first inventor. These runner-up patents increase social welfare under very general conditions. Furthermore, we show that the time window during which later inventors can share the patent should become a new policy tool at the disposal of the designer. This instrument will be used in a socially optimal mix with the breadth and length of the patent and could allow sorting between more or less efficient firms.
\end{abstract}

Keywords: Patents; second inventor; deadweight loss; optimal mix of instruments JEL classification: O38; O34; O31; L12

\section{Introduction}

In 1976 Eugene Goldwasser, after 20 years of work, successfully identified and isolated the erythropoiesis protein (EPO), whose function is to produce red blood cells in the body. His work attracted the attention of three companies, Biogen, Amgen, and the Genetics Institute, which started research programs to isolate the human gene responsible for the production of EPO. In 1983, Amgen succeeded and filed for a patent at the US Patent Office. Less than a year later, the Genetics Institute published similar results in the journal Nature but realized its success was economically pointless because a patent had already been submitted. The drug Epogen, subsequently sold by Amgen, became one of the most successful in history, generating revenues of two billion dollars per year, an annual treatment costing, 5,000 dollars per patient. Amgen appears to be fully exercising its monopoly power at the expense of patients and government medical assistance programs. $^{1}$

\footnotetext{
*I wish to thank particularly Douglas Bernheim for his generous support and advice. This research was supported by the Leonard W. Ely and Shirley R. Ely Graduate Student Fund through a grant to the Stanford Institute for Economic Policy Research.

${ }^{1}$ The cost of production represents approximately $5 \%$ of the revenues, and the initial investment in research did not exceed 170 million dollars.
}

(C) The editors of the Scandinavian Journal of Economics 2010. Published by Blackwell Publishing, 9600 Garsington Road, Oxford, OX4 2DQ, UK and 350 Main Street, Malden, MA 02148, USA. 
Recent empirical evidence (Cohen and Ishii, 2005) suggests that quasisimultaneous invention, as in the case of Epogen, is not a rare event. Cohen and Ishii (2005) use patent interference cases in the US to overcome the empirical challenge that the second inventor is typically not observed. A patent examiner has to declare an interference if two inventors file for the same invention within a short time period (three months for lesser inventions and six months for more important ones). ${ }^{2}$ They show that from 1988 to $1994,0.6 \%$ of granted patents were declared in interference, and $2.14 \%$ were for drugs and $4.97 \%$ for biotech. We believe that the percentage of quasi-simultaneous inventions is likely to exceed these numbers for two reasons. First, these are percentages of the total number of patents awarded, and only a fraction of these will prove valuable. ${ }^{3}$ Moreover, it is likely that quasi-simultaneous invention occurs mostly for valuable ideas. Second, the window to declare an interference is short (maximum of six months).

In this paper, we build on this empirical evidence to address the following question. Would it be socially beneficial to let later inventors, such as the Genetics Institute, share the patent if they discover soon enough after the first inventor? The current patent system grants socially costly exclusive rights to first inventors to encourage risky investments in research. We want to determine if an efficient trade-off between incentives to innovate and deadweight loss on the product market can be achieved without necessarily awarding monopolies. We therefore study an alternative mechanism, which we call runner-up patents, whereby if a first inventor files for a patent at time $t$, any other inventor who discovers before time $t+T$ is allowed to share the patent and compete on the product market.

We study this alternative mechanism in a theoretical model where firms first race for an innovation and then potentially compete in the product market. We show that under very general conditions, runner-up patents increase social welfare. We can separate their overall impact into two channels: they affect both incentives to innovate and deadweight loss on the product market. In most cases, runner-up patents decrease incentives to innovate. However, the second effect is always positive, because this mechanism induces socially beneficial competition in the product market. We show that under a very general condition, this second effect more than compensates the first.

We consider the time window $T$ (time period starting after the first inventor succeeds and during which later inventors are still allowed to patent),

\footnotetext{
${ }^{2}$ The patent office then investigates the case more thoroughly to determine the identity of the first inventor.

${ }^{3}$ The distribution of patent values is known to be heavily skewed (see Harhoff, Narin, Scherer, and Vopel, 1999).
} 
which we name patenting window, as a new tool at the disposal of the policy-maker. In the results previously mentioned, the existing patent policy tools, such as the length and breadth of the patent, were supposed fixed. In the second part of the paper, we ask a different question. Is the patenting window a redundant tool or can it achieve a more efficient trade-off between incentives to innovate and deadweight loss than the existing instruments? We therefore examine the optimal mix with the length and breadth of the patent. We show that under very general conditions the patenting window is more efficient than these existing tools.

Finally, we demonstrate that the patenting window could become a very useful sorting tool. We show that the designer could sort between more or less efficient firms by offering a menu of patents where the inventor could trade off a longer patenting window against a longer length. An efficient firm would be willing to take the risk of allowing other firms to patent during a certain time period in exchange for a longer protection. A welldesigned menu could therefore increase the incentives to innovate for the more efficient firm.

Runner-up patents could probably be implemented relatively easily in practice. One concern could be that following disclosure by the first inventor, the follower could easily copy the invention. However, under current patent law, the details of the invention are only publicly disclosed 18 months after the filing date of the patent application. So introducing a patenting window of 18 months would only require minor changes to the current patent system. Such a minor reform could already have important consequences. In the case of Epogen, we calculate that runner-up patents with an 18-month patenting window could have increased the discounted expected social welfare at the start of the race between Amgen and the Genetics Institute by close to one billion dollars. ${ }^{4}$

In Section II we derive a general condition guaranteeing that runnerup patents increase social welfare. In Section III we examine the optimal mix of instruments. In Section IV we consider the patenting window as a sorting tool. Several articles-La Manna, Macleod, and de Meza (1989), Maurer and Scotchmer (2002), and Shapiro (2006) - build on similar concerns about the current patent system and argue for a more permissive environment. We discuss the links with these papers in Section V. We also discuss the connections between the patenting window and the classical notion of breadth. All proofs are presented in the Appendix.

\footnotetext{
${ }^{4}$ We obtain this figure by tailoring our model to that application. We fix the expected speed of the Poisson research at seven years (this was the length of the research performed by the two successful firms). We also assume linear demand on the product market and Cournot competition. We use the observed monopoly profits obtained by Amgen (in the order of US $\$ 1.9$ billion) to adjust profits and surplus. Finally we assume an interest rate of $3 \%$.
} 


\section{Runner-up Patents and Social Welfare}

\section{The Model}

We consider a model where two risk-neutral symmetric firms race to obtain an innovation. ${ }^{5}$ At date 0 they determine their investments in research $\left(x_{1}, x_{2}\right)$. The investment $x_{i}$ is sunk initially and determines the speed of the research process. Specifically, the distribution of discovery time for firm $i$ is a Poisson process of parameter $h\left(x_{i}\right){ }^{6}$

Two main instruments characterize the patent system: the length of the patent $L$ and the patenting window $T$ (with $L \geq T$ ). If the first firm to succeed obtains the invention at date $t$, the second firm can still patent and share the market if it invents before date $t+T$. In this case the two firms share the market. If the second firm is unable to succeed within this window, the first obtains exclusive rights until expiration of the patent. At $t+L$ the patent expires and the market is then characterized by free entry. We note that for $T=0$ this model is a classical description of the current regulatory system.

Firms maximize their expected profits. If the first inventor obtains the exclusive patent, she collects a flow of monopoly profits $\pi_{m}$ until the patent expires at $t+L$. If the firms share the patent, they both obtain a flow of duopoly profits $\pi_{d}$. Total social welfare under monopoly is denoted $S_{m}$ and $S_{d}$ under duopoly.

Finally, we make a number of assumptions on the shape of the discovery process that guarantee the existence of an equilibrium where both firms invest in research under the current patent system where $T=0$. If the research process is such that this equilibrium does not exist, at most one firm conducts research, and runner-up patents are irrelevant. We therefore exclude these cases from our analysis by making the following assumptions on the function $h$ that characterizes the research process:

\footnotetext{
${ }^{5}$ It is important to point out that if the firms were sufficiently risk averse, runner-up patents would always increase incentives to innovate. Indeed, one of the main effects of this system is to provide positive profits in a wider range of cases; profits can now be obtained by a firm that is not the first to invent. Therefore, for a sufficient degree of risk aversion, runner-up patents would always appear more attractive than the standard patents. To abstract from the impact of risk aversion and concentrate on other effects, we suppose that inventors are risk neutral.

${ }^{6}$ Note that we assume that the second inventor does not adapt his research effort after observing the success of the first; that is, both $x_{1}$ and $x_{2}$ are determined initially. This is sensible for two reasons. First, the second inventor might not observe success of the first. For instance in the current patent system, when an application is being reviewed, it is not made public. Second, most of our results are established for small patenting windows, leaving little time for the second inventor to change his research strategy.
} 
Assumption 1. $h(0)=0$.

Assumption 2. $h^{\prime}(0)=+\infty$.

Assumption 3. $h$ is increasing, twice continuously differentiable, and concave.

\section{Runner-up Patents and Social Welfare}

As pointed out in the Introduction, runner-up patents have two effects: an ex ante effect on incentives to innovate and an ex post effect on social surplus. This section examines the direction of these effects and the overall impact on social welfare in the case of an infinite patent length $(L=+\infty)$.

The expected profits of the innovators, at the start of the race, are given by the expression:

$$
\frac{h\left(x_{1}\right) V_{W}+h\left(x_{2}\right) V_{L}}{h\left(x_{1}\right)+h\left(x_{2}\right)+r}-x_{1},
$$

where

$$
\begin{aligned}
V_{W}= & \int_{0}^{T}\left[\frac{\pi_{m}}{r}\left[1-e^{-r t_{2}}\right]+\frac{\pi_{d}}{r}\left[e^{-r t_{2}}\right]\right] h\left(x_{2}\right) e^{-h\left(x_{2}\right) t_{2}} d t_{2} \\
& +\frac{\pi_{m}}{r} \int_{T}^{+\infty} h\left(x_{2}\right) e^{-h\left(x_{2}\right) t_{2}} d t_{2}
\end{aligned}
$$

is the expected pay-off to firm 1 if it wins the race, and

$$
V_{L}=\int_{0}^{T} \frac{\pi_{d}}{r}\left[e^{-r t}\right] h\left(x_{1}\right) e^{-h\left(x_{1}\right) t} d t
$$

is the expected profit of firm 1 if it loses the race.

Innovators choose their investments in research to maximize their expected profits at the start of the race. The first-order conditions can be expressed as

$$
\begin{aligned}
{\left[h\left(x_{1}\right)+h\left(x_{2}\right)+r\right]^{2}=} & h^{\prime}\left(x_{1}\right)\left[\left(h\left(x_{2}\right)+r\right) V_{W}-h\left(x_{2}\right) V_{L}\right] \\
& +h\left(x_{2}\right) V_{L}^{\prime}\left(x_{1}\right)\left(h\left(x_{1}\right)+h\left(x_{2}\right)+r\right) .
\end{aligned}
$$

Since firms are symmetric, we concentrate on the symmetric equilibrium where $x_{1}=x_{2}=x^{*}$. Furthermore, we concentrate on limit results for small patenting windows; that is, the case where $T=0$. The symmetric equilibrium for $T=0$ is characterized by

$$
\frac{h^{\prime}\left(x^{*}\right)\left(h\left(x^{*}\right)+r\right)}{\left(2 h\left(x^{*}\right)+r\right)^{2}} \frac{\pi_{m}}{r}=1 .
$$


In the following proposition, we use the first-order conditions to establish that the first effect of runner-up patents on incentives to innovate is negative under a general condition on profits. Runner-up patents therefore tend to decrease incentives to innovate.

Proposition 1. If $\pi_{m} \geq 2 \pi_{d}$, runner-up patents decrease the equilibrium investment in research: $\left(d x^{*} / d T\right)(0)<0$.

If monopoly profits are larger than aggregate profits under duopoly, runner-up patents decrease incentives to innovate. The intuition for this result is more transparent in the context of a simple one-period game where each firm succeeds with a fixed probability $p$. Under the current patent system, the expected profits of a firm engaged in the race is $\pi_{\text {current }}=p(1-p) \pi_{m}+p^{2} \frac{1}{2} \pi_{m}$ (if they both succeed, one will be randomly chosen to obtain the exclusive patent). With runner-up patents in place, the profits become $\pi_{\text {runner-up }}=p(1-p) \pi_{m}+p^{2} \pi_{d}$. The relevant comparison is indeed between $2 \pi_{d}$ and $\pi_{m}$. With a certain probability, both firms simultaneously discover. With runner-up patents, rather than obtaining monopoly profits with a probability of one-half, firms have to compete for the market and collect profits $\pi_{d}{ }^{7}$

Many markets satisfy the condition of Proposition 1. However, we can also easily find examples where this condition is violated. This can be the case if for instance the invention can have different applications and if licensing contracts are hard to negotiate. ${ }^{8}$ It could also be the case if the two firms invent differentiated products. In general, if the condition is violated, runner-up patents will assuredly be socially beneficial. They both increase research incentives and decrease the deadweight loss on the market.

Proposition 1 indicates that runner-up patents generally decrease incentives to innovate. However, there exists a countervailing effect. Runnerup patents increase competition on the product market and therefore decrease deadweight loss after the invention has been obtained. The

\footnotetext{
${ }^{7}$ A similar point was made in Maurer and Scotchmer (2002) in Proposition 2, where they point out that independent-invention defense would tend to decrease research incentives and thus duplicative research.

${ }^{8}$ For instance, marketing a product for specific groups of customers can increase aggregate profits, and this might be better achieved by two different firms. This of course raises the issue of why the first inventor would not license to a second firm. The case of Epogen again provides a good example. Amgen licensed its drug to Johnson \& Johnson in 1985 to try and efficiently split the market; Epogen targeted the kidney disease patients, whereas Procrit sold by Johnson \& Johnson marketed it for cancer-related anemia. However, Amgen claims that the licensing agreement was abused and Procrit was invading its market. This episode suggests why certain companies might avoid licensing contracts and why, therefore, having two competitors might increase aggregate profits.
} 
following proposition examines the overall effect on social welfare. We obtain conditions such that the expected social welfare is increasing in $T$ at $T=0$.

Proposition 2. Runner-up patents are socially beneficial under the following condition:

$$
-\left[S_{m}-\pi_{m}\right]\left[\pi_{m}-2 \pi_{d}\right]+\pi_{m}\left[S_{d}-S_{m}\right]>0 .
$$

In particular this will be the case if

(a) social surplus under competition is high enough: $S_{d}>2 S_{m}$;

(b) private and social benefits under monopoly are comparable $S_{m}\left[r / h\left(x^{*}\right)+r\right]<\pi_{m}$

(c) demand is linear, both for Cournot and Bertrand competition.

According to result (a), if the surplus under competition is high enough compared to that under monopoly, runner-up patents are socially beneficial regardless of the nature of demand, competition, or the research process. The intuition for this result is that if surplus is much higher under duopoly, the gains from increased competition (second term in the characteristic equation) more than compensate the loss of incentives (first term), even in the worst-case scenario of zero profits under duopoly. Result (c), on the other hand, studies the case of a particular functional form: if demand is linear, departing from the current winner-take-all system is always beneficial, irrespective of the type of competition.

Result (b) states that if private and social benefits under monopoly are not too different, runner-up patents always increase social welfare. In the presentation of the results, we have chosen to separate the impact of these patents into two effects (ex ante incentives and ex post deadweight loss) and to present an increase in research incentives as always being socially desirable. This simplification in the exposition was aimed at providing a clear presentation of the different channels, although all the results were obtained directly by maximizing the expected social welfare. Case (b) illustrates the fact that decreasing incentives can actually be beneficial if the research conducted under the current system was already excessive. If, for example, private and social benefits under monopoly are equal $\left(S_{m}=\pi_{m}\right)$, a unique firm chooses the socially optimal amount of research. ${ }^{9}$ If a competitor enters the race, research in excess of this optimum will therefore be conducted. Runner-up patents are then beneficial on two accounts: they decrease incentives to innovate, and they decrease deadweight loss.

\footnotetext{
${ }^{9}$ Loury (1979) makes this assumption that social and private benefits are equal $\left(S_{m}=\pi_{m}\right)$ and logically finds in Section IV of his paper, where he studies the welfare analysis of patent races, that firms conduct a socially excessive amount of research.
} 


\section{Optimal Mix of Patent Policy Tools}

In the previous section we assumed that the existing patent policy tools (length and breadth) were fixed ${ }^{10}$ and showed that introducing a new instrument, the patenting window, was socially beneficial. However, all these tools can trade off incentives to innovate against deadweight loss in the product market in very different ways. ${ }^{11}$ Therefore we cannot yet rule out that runner-up patents appear socially beneficial only because the other existing tools are not optimally set.

To fully evaluate the benefits from runner-up patents, we therefore need to address a broader question: is the patenting window a redundant tool or can it achieve a more efficient trade-off between these two effects? To answer this question, we study the optimal mix of these instruments. In particular we determine conditions under which a socially optimal mix will include a strictly positive patenting window.

\section{General method}

We first describe the general method to determine the socially optimal mix between the patenting window $T$ and the existing tools: length $L$ and breadth $\alpha$. This method will use the results of the previous section. A socially optimal mix of these instruments will induce a specific amount of research at the lowest cost in terms of social welfare. We therefore need to solve the problem of maximizing expected social surplus $S(T, L, \alpha)$, given that the equilibrium amount of research $x^{*}(T, L, \alpha)$ is greater than a certain value $\bar{x}$.

The method follows these steps:

(1) Determine the Nash equilibrium of the research phase $x^{*}(T, L, \alpha)$.

(2) Determine the expected social surplus $S(T, L, \alpha)$, given the equilibrium amount $x^{*}$.

(3) Solve for $\left(T^{*}, L^{*}, \alpha^{*}\right)$ solution to:

$$
\max _{T, L, \alpha} S(T, L, \alpha) \quad \text { subject to } T \geq 0 \text { and } T \leq L \text { and } x^{*} \geq \bar{x} .
$$

(4) Use the Kuhn-Tucker conditions to obtain a condition guaranteeing that $T^{*}>0$.

\footnotetext{
${ }^{10}$ In particular the length was fixed at $L=+\infty$.

${ }^{11}$ For instance, decreasing the length of the patent decreases research incentives, as competitors are allowed to enter earlier, but also decreases deadweight loss on the market.
} 


\section{Optimal Mix of Instruments}

We apply the method previously described to determine whether the patenting window will be used in an optimal mix with the length and breadth of the patent. Whereas the length is a straightforward concept (the law specifies a patent's expiration date), the breadth of a patent does not have a clear legal specification. In general terms, it describes how various innovations need to be in order to avoid infringing on their respective patents. From this intuitive definition, we understand that a lot of discretion is left to the patent office and the courts in making this decision. This concept of breadth has therefore been modeled in a variety of ways in the literature. We will discuss this point more systematically in Section V.

One general model by Denicolo (1996), more specifically adapted to the study of patent races, covers most of the different definitions of breadth. Following Denicolo's approach, we suppose that as soon as the first inventor succeeds, the competitor obtains profits $\pi_{L}(\alpha)$ where $1-\alpha$ measures the breadth of patents. The idea is that during the research process, the loser accumulates knowledge that will allow him to compete more efficiently with the patented product (for example, it makes designing a non-infringing version of the product less costly to develop), and a larger breadth makes this competition more difficult. In the presence of runner-up patents, however, the second competitor might continue searching until $t+T$. We also suppose that both profits and social surplus depend on the abstract parameter $\alpha ; \pi_{m}(\alpha)$ is decreasing in $\alpha$, and $\pi_{L}(\alpha)$ and $S_{m}(\alpha)$ are increasing. In the following proposition, we derive under which conditions the patenting window will be used in a socially optimal mix of instruments.

Proposition 3. The socially optimal mix $\left(T^{*}, L^{*}, \alpha^{*}\right)$ will require the patenting window $T^{*}$ to be strictly positive if the following conditions are satisfied:

$$
\begin{gathered}
\frac{S_{d}-S_{m}}{\pi_{m}+\pi_{L}-2 \pi_{d}}>\frac{S_{0}-S_{m}}{\pi_{m}+\pi_{L}}, \\
\frac{S_{d}-S_{m}}{\pi_{m}+\pi_{L}-2 \pi_{d}}>-\frac{S_{m}^{\prime}(\alpha)}{\pi_{m}^{\prime}(\alpha)-\pi_{L}^{\prime}(\alpha)} .
\end{gathered}
$$

Both conditions compare ratios of social benefits over loss of incentives from the different tools. ${ }^{12}$ Condition (1) guarantees that the patenting window is more efficient than the length, whereas condition (2) compares it to the breadth. To be more specific, condition (1) compares the ratio of

\footnotetext{
${ }^{12}$ These are similar to the ratio test presented in Scotchmer (2004, Ch. 4). It is obtained here in a context with three instruments and patent races.
} 
social benefits over loss of incentives from the patenting window on the left-hand side and the length on the right. ${ }^{13}$ Corollaries 1 to 3 provide interpretations of these results. We start by analyzing the optimal mix with the length.

\section{Corollary 1.}

(a) Condition (1) is satisfied for Cournot competition and linear demand.

(b) For Bertrand competition, the marginal effects of both tools are equal. Moreover, at the limit, for small departures from Bertrand competition, the condition is strictly satisfied.

Condition (1) depends exclusively on the nature of demand in the product market and the type of competition. In particular, result (a) states that for linear demand and Cournot competition, the patenting window is more efficient than the length. Result (b), on the other hand, holds independent of the type of demand. It underlines an essential difference between the length and the patenting window. At first glance, both tools seem very similar. Indeed, for Bertrand competition, they both replace monopoly by perfect competition, and their marginal effects are therefore identical. However, the corollary also points out that for small deviations from Bertrand competition, such as small rigidities in prices, the condition is strictly satisfied.

The intuition for this result is that, for small departures from Bertrand competition, increasing the patenting window has a smaller marginal effect on social surplus than decreasing the length, but it also creates a smaller reduction in incentives because the second inventor can obtain duopoly profits. However, social surplus is maximal at Bertrand prices. The effect on social surplus is therefore of second order whereas the change in incentives is of first order. The patenting window therefore achieves, at the margin, a more efficient trade-off between ex ante incentives and ex post surplus than the length.

This result also reflects an essential difference between these tools. They both encourage competition, but the origin of this competition proves to be the key difference. If the length is reduced, competition comes from outside imitators (for example, for pharmaceutical companies, firms producing generics), whereas if the patenting window is increased, only innovators inside the race will compete. Therefore, to achieve the same gain in social

\footnotetext{
${ }^{13}$ With the patenting window, a marginal increase of $T$ causes monopoly to be replaced by duopoly at the margin. The social gain is therefore proportional to $S_{d}-S_{m}$, whereas the expected profit is reduced from monopoly profits with probability 0.5 to duopoly profits. The loss in terms of incentives is therefore proportional to $0.5\left(\pi_{m}+\pi_{L}\right)-\pi_{d}$. A marginal reduction in the length $L$ leads to a social gain of $S_{0}-S_{m}$ for a loss of incentives of $\pi_{m}+\pi_{L}$.
} 
surplus, it is less costly in terms of incentives to use the patenting window as innovators inside the race can get partial compensation. ${ }^{14}$ The origin of competition is the essential difference between these tools.

As previously stated, condition (2) reflects a similar comparison between the patenting window and the breadth. It is, however, more difficult to interpret because the concept of breadth is represented by an abstract parameter. We therefore propose two examples to illustrate the result, following examples in Denicolo (1996).

The first example is a case of horizontal differentiation à la Hotelling, where consumers are distributed on the line $(0,1)$ and incur a transport cost $t$. We suppose the two firms propose differentiated products and are located at 0 and 1 . They initially produce two goods of quality $\bar{\theta}$ at zero cost. They are engaged in a patent race to obtain an innovation that raises the quality to $\bar{\theta}+\widehat{\theta}$. As soon as one invents, the other can produce a good of quality $\bar{\theta}+\alpha \widehat{\theta}$. However, in our set-up, the second firm can also continue its research effort until the expiration of the patenting window. We assume that a consumer that buys one unit of good $i$ obtains utility $U=\theta_{i}-t d_{i}-p_{i}$, where $p_{i}$ is the price and $d_{i}$ the distance to the product. Given these assumptions, we obtain the following result.

Corollary 2. In the case of horizontal differentiation, condition (2) is always satisfied.

The second example is a case of process innovation in a Cournot duopoly. The demand function is given by $p=a-Q$. Before the innovation, both firms produce at constant marginal cost $c=a$ and make zero profits. The innovation reduces the marginal cost to $c-d$. As in the previous example, the loser in the race may still appropriate some of the rents. More specifically, we suppose the loser can produce at marginal cost $c-\alpha d$.

Corollary 3. In this specific case of a process innovation in a Cournot duopoly, condition (2) is always satisfied.

\section{Patenting Window as a Sorting Tool}

This section illustrates another potential use of the patenting window: it could become an efficient sorting tool. Specifically, we suppose that, at the invention date, the first firm to succeed is offered the choice between different menus $(T, L)$ such that it can trade off a higher patenting window $T$ against a longer length $L$ of protection. For example, the patent office could offer the first inventor the choice between the menus ( $T=0$ months,

\footnotetext{
${ }^{14}$ They obtain a compensation if they are second in the race, reflected in the smaller cost in terms of incentives $\pi_{m}+\pi_{L}-2 \pi_{d}$ rather than $\pi_{m}+\pi_{L}$.
} 
$L=18$ years) and ( $T=18$ months, $L=22$ years). We illustrate in this section potential benefits from such menus.

The breadth and renewal fees have been proposed as sorting instruments in the literature. Cornelli and Schankerman (1999) and Scotchmer (1999) showed that efficient sorting could be achieved with a menu of patent lives and associated renewal fees. More recently, Hopenhayn and Mitchell (2001) provided a set of conditions under which a menu of breadth and length is a more efficient sorting tool than renewal fees are. We follow the lines of this literature, but we want to point out that menus using the patenting window are easier to implement than menus with breadth. ${ }^{15}$

An important concern expressed in the literature on patent races is that the current uniform patent system provides the same research incentives to all firms, regardless of their efficiency. The incentives are therefore excessive for the less efficient firms and insufficient for the more efficient ones. Currently, it is not possible to sort between these types. We suggest in this section that using menus $(T, L)$ can help achieve that goal. In the case where the different types are determined by the speed of their research process $\lambda$, we obtain the following result.

Proposition 4. The decision-maker can use menus $(T, L)$ to provide higher types with higher expected profits at the start of the race.

The intuition of this result is the following. If a highly efficient type is the first to succeed, she does not place a high probability on the event that a less efficient competitor will succeed soon afterwards. Therefore the marginal value of a smaller patenting window is smaller for her, and she is ready to face more risk in exchange for a longer protection. She can therefore obtain a positive rent in the contract-signing phase.

\section{Discussion and Links with the Literature}

A number of contributions (La Manna et al., 1989; Maurer and Scotchmer, 2002; Shapiro, 2006) argue for a more permissive patent system. In this section, we discuss those contributions in detail and also examine more closely the links between the concept of breadth and our notion of patenting window. We note that there is also a related body of literature on the allocation of prizes in contests (Moldavanu and Sela, 2001; Szymanski and Valetti, 2005). However, in this body of literature, the goal is to design a contest that maximizes effort. The ex post effect on social surplus that concerns us is not relevant in their framework.

\footnotetext{
${ }^{15}$ The concept of breadth is already hard to define precisely, so it is probably impossible to contract on.
} 
In an important paper, La Manna et al. (1989) examine the following set-up: during the entire life of the patent, other inventors are allowed to patent as well. They identify conditions under which this permissive system is socially preferable to a stricter one. They do not consider strategic investment in research but rather allow for free entry in the innovation market. In our case, we limit the model to two inventors given that we enrich it along other dimensions. ${ }^{16}$

Maurer and Scotchmer (2002) examine the impact on licensing incentives of allowing independent inventors to patent. They show that in such circumstances the first inventor would license her technology in order to discourage investments in imitation. They conclude that, under the condition that the research costs of an imitator are more than half as high as those of the initial inventor, the first inventor is able to fully deter entry by competitors by granting a sufficient number of licenses. The focus of their work is complementary to ours. They examine incentives of imitators once an innovation has been adopted. We, on the other hand, study how modifying the regulatory environment will affect firms racing to obtain the innovation.

The most related contribution is a paper independently and simultaneously written by Shapiro (2006), which is a fitting example of simultaneous invention. In a reduced-form timeless model, the paper examines the introduction of prior-user rights. Given that timing is not explicitly considered, prior-user rights are equivalent to independent-invention defense. The main result of the paper, Theorem 1, identifies a condition that guarantees that the introduction of independent-invention defense is socially optimal. The condition they identify proves to be similar to condition (2) in Proposition $3 .{ }^{17}$ Our analysis therefore confirms the result of Theorem 1 in a model where the timing of the innovation is made explicit.

These different papers argue in favor of a more permissive patent system. Such considerations are also emerging in the law literature; see, for instance, Lemley (2007). We point out, however, that a recent contribution by Denicolo and Franzoni (2010) challenges this view, in particular in the case where research costs are incurred as a flow. Introducing runner-up patents would represent a major regulatory reform, and it is therefore important to consider the results' robustness to different assumptions. It is also essential to understand the details of the implementation. One of the benefits of introducing a model where timing is explicit is that we can be more precise about the benefits of such a reform. We argue in our paper in

\footnotetext{
${ }^{16}$ Introducing a larger number of inventors would require keeping track of all invention dates, and calculations would quickly become intractable.

${ }^{17}$ In the proof of Theorem 1, Shapiro calculates the social benefits of introducing prior-user rights (or independent-invention defense) given a length of patents that is optimally set.
} 
favor of the introduction of a new instrument of patent policy: the patenting window. We unveil conditions under which it is more efficient than the existing instruments. We also show that it can become an efficient sorting tool.

\section{Patenting Window and Breadth}

The analysis in the previous sections has highlighted the fact that the patenting window has similarities with the notion of breadth. This section examines these links more thoroughly. We start by looking at the various definitions of breadth that can be found in the literature.

The breadth of the patent, as opposed to the length, is not a legally welldefined concept. It measures in general how different an invention needs to be to warrant a patent. Various representations of breadth have been proposed. In the case of a process innovation (invention that is aimed at developing a technology to reduce the cost of production), Nordhaus (1972) defines breadth as the fraction of cost reduction that does not become freely available to competing firms. Gallini (1992) develops a related concept and models a wider patent as increasing the cost of imitation for competing firms. Klemperer (1990) does not consider costs but directly studies a case with differentiated products. He defines the breadth of the patent as the distance in the characteristic space between the patented innovation and the non-infringing products of the competitors.

In Section III we compared how efficient the patenting window is compared to the breadth of the patent in balancing ex ante research incentives and ex post deadweight loss. We compared it explicitly to specific notions of breadth in Corollaries 2 and 3. Some of the results nevertheless suggest that our notion of the patenting window is formally equivalent to a notion of breadth. This is not the case. Denicolo (1996) proposes a unifying framework for these different notions of breadth and summarizes the concept in a single parameter $\alpha$ that parametrizes both the winner's and the loser's profit in the innovation race. The patenting window does not, however, fit this definition given its time dependency. The way this new instrument influences the profits of winners and losers depends on the respective dates of invention.

The best conceptual representation of the patenting window is in fact a time-varying breadth. Following discovery by the first inventor, the patent is narrow (i.e., inventions with very similar claims are patentable) until the expiration of the patenting window, when it becomes wider. It is in fact conceivable that such a notion is already implicitly applied by patent examiners and courts. It would be an interesting empirical exercise to test whether, in patent infringement suits, a patent is more likely to be found not to infringe if its invention date is close to that of the initial patent. 


\section{Conclusion}

We have shown in this article that runner-up patents increase social welfare in a wide variety of cases. We also showed that the patenting window could become an essential tool of patent policy. We provide conditions under which it can trade off incentives to innovate against deadweight loss more efficiently than the existing instruments, such as the length and breadth of the patent. We also suggest that it could become an essential sorting tool that could allow, for instance, an increase in the research incentives of more efficient firms.

This work could be extended in a number of ways. An interesting direction would be to understand how runner-up patents might influence the patenting of intermediate products. On the one hand, the incentives to patent intermediate inventions are decreased because firms do not necessarily lose everything if the competitor patents before them. On the other hand, runnerup patents will decrease the cost of disclosing the discovery ${ }^{18}$ and might therefore increase the incentives to disclose intermediate results. A different model, allowing for cumulative inventions, will have to be proposed to determine which of these two effects will dominate.

We also believe that we can further explore the idea of the patenting window as a sorting tool. We have focused on menus that trade off the patenting window against length. It could also be interesting to study menus that trade off the patenting window against the breadth of the patent. Moser (2005) shows that in sectors where secrecy is a good defense, patents will not be an attractive alternative. This secrecy is socially costly since knowledge is not shared. It will therefore be important to design ways of bringing these firms back to the patent system. A firm for which secrecy is a good alternative might find the current uniform breadth not large enough to compensate for the disclosure of its invention. However, such a firm could be willing to trade off a higher patenting window (similar to taking the risk of secrecy) against a larger breadth. Such a menu could be attractive enough to make the patent system a serious alternative.

\section{Appendix}

\section{Proof of Proposition 1}

The symmetric equilibrium $x^{*}$ described in the main text is the solution to the following:

\footnotetext{
${ }^{18}$ Even if the competitor obtains useful information from the disclosure and is quicker to develop an improvement, runner-up patents might still allow them to share the patent.
} 


$$
\begin{aligned}
& \pi_{m}(h(x)+r)+\pi_{d} T\left[(h(x))^{2} \frac{2 h(x)+r}{h(x)+r}\right] e^{-(r+h(x)) T} \\
& \quad+\pi_{d}\left(1-e^{-(r+h(x)) T}\right)\left[r \frac{h(x)(2 h(x)+r)}{(h(x)+r)^{2}}-\frac{h(x)^{2}}{h(x)+r}\right] \\
& \quad+\left(\pi_{d}-\pi_{m}\right)\left(1-e^{-(r+h(x)) T}\right) h(x) \\
& =\frac{r(2 h(x)+r)^{2}}{h^{\prime}(x)} .
\end{aligned}
$$

This equation for $T=0$ yields the result expressed in the main text.

Furthermore, we show that the second-order conditions are also verified at $T=0$, given that $h$ is concave:

$$
\frac{\pi_{m}}{r} \frac{h^{\prime \prime}(x)(2 h(x)+r)-2 h^{\prime}(x)^{2}}{(2 h(x)+r)^{3}}<0 .
$$

To determine how the amount of research performed varies with the patenting window $T$, we take the total derivative of the first-order conditions previously obtained.

$$
\begin{aligned}
0= & \mathbf{d x}\left[\pi_{m} h^{\prime}(x)-r \frac{4 h^{\prime 2}(2 h(x)+r)-h^{\prime \prime}(x)(2 h(x)+r)^{2}}{h^{\prime}(x)^{2}}\right] \\
& +\mathbf{d T}\left[\pi_{d} h(x)^{2} \frac{2 h(x)+r}{h(x)+r}+\pi_{d}\left[r \frac{h(x)(2 h(x)+r)}{(h(x)+r)}-h(x)^{2}\right]\right. \\
& \left.+\left(\pi_{d}-\pi_{m}\right)(r+h(x)) h(x)\right] .
\end{aligned}
$$

Simplifying this expression, we obtain

$$
\frac{d x}{d T}=\frac{\left(\pi_{m}-2 \pi_{d}\right)(r+h(x)) h(x)}{\pi_{m} h^{\prime}(x)-r \frac{4 h^{\prime}(x)^{2}(2 h(x)+r)-h^{\prime \prime}(x)(2 h(x)+r)^{2}}{h^{\prime}(x)^{2}}} .
$$

To determine the sign of this expression, we use the first-order conditions characterizing the equilibrium $x^{*}$ :

$$
\frac{h^{\prime}\left(x^{*}\right)\left(h\left(x^{*}\right)+r\right)}{\left(2 h\left(x^{*}\right)+r\right)^{2}} \frac{\pi_{m}}{r}=1 .
$$

So, we can express the denominator as

$$
r \frac{(2 h(x)+r)^{2}}{h(x)+r}-r 4(2 h(x)+r)+r \frac{h^{\prime \prime}(x)}{h^{\prime}(x)^{2}}(2 h(x)+r)^{2}<0 .
$$

Therefore, if $\pi_{m}>2 \pi_{d}$, we find that $\left(d x^{*} / d T\right)(0)<0$.

\section{Proof of Proposition 2}

We first prove the following lemma that provides sufficient conditions guaranteeing that runner-up patents are socially beneficial. 
Lemma 1. Runner-up patents are socially beneficial if

$$
-\left[S_{m}-\pi_{m}\right]\left[\pi_{m}-2 \pi_{d}\right]+\pi_{m}\left[S_{d}-S_{m}\right]>0 .
$$

Proof: We first calculate the expected social welfare function at the start of the race, given that both competitors in the symmetric equilibrium invest $x^{*}$. The instantaneous social benefit if the two firms do not innovate within $T$ of each other is the social surplus from monopoly $S_{m}$. If they invent within $T$ of each other, $S_{m}$ until the loser succeeds and $S_{d}$ from then on. We have

$$
\begin{aligned}
W(T)= & \frac{2 S_{m}}{r} \int_{0}^{+\infty} e^{-r t} h\left(x^{*}\right) e^{-h\left(x^{*}\right) t} \int_{t+T}^{+\infty} h\left(x^{*}\right) e^{-h\left(x^{*}\right) t_{2}} d t_{2} d t \\
& +2 \int_{0}^{+\infty} h\left(x^{*}\right) e^{-h\left(x^{*}\right) t} \int_{t}^{t+T}\left[\frac{S_{m}}{r}\left[e^{-r t}-e^{-r t_{2}}\right]+\frac{S_{d}}{r}\left[e^{-r t_{2}}\right]\right] \\
& \times h\left(x^{*}\right) e^{-h\left(x^{*}\right) t_{2}} d t_{2} d t-2 x^{*} .
\end{aligned}
$$

Simplifying and factoring, we find

$$
\begin{aligned}
W(T)= & \frac{S_{m}}{r} \frac{2 h\left(x^{*}\right)}{2 h\left(x^{*}\right)+r}+\left[1-e^{-\left(h\left(x^{*}\right)+r\right) T}\right]\left[\frac{S_{d}-S_{m}}{r}\right] \\
& \times\left[\frac{2 h\left(x^{*}\right)^{2}}{\left(h\left(x^{*}\right)+r\right)\left(2 h\left(x^{*}\right)+r\right)}\right]-2 x^{*} .
\end{aligned}
$$

Taking the derivative at $T=0$, we find the following first-order conditions:

$$
\frac{d x^{*}}{d T}(0)\left[\frac{S_{m}}{\pi_{m}} \frac{r}{h\left(x^{*}\right)+r}-1\right]+\frac{S_{d}-S_{m}}{r} \frac{h^{2}\left(x^{*}\right)}{2 h\left(x^{*}\right)+r}>0 .
$$

As $\left(d x^{*} / d T\right)(0)<0$, a sufficient condition is

$$
\frac{d x^{*}}{d T}(0)\left[\frac{S_{m}}{\pi_{m}}-1\right]+\frac{S_{d}-S_{m}}{r} \frac{h^{2}\left(x^{*}\right)}{2 h\left(x^{*}\right)+r}>0 .
$$

Furthermore, we can rewrite $d x / d T$ as

$$
\frac{d x}{d T}=\frac{\left(\pi_{m}-2 \pi_{d}\right)(r+h(x)) h(x)}{r \frac{(2 h(x)+r)(-2 h(x)-3 r)}{(h(x)+r)}+r \frac{h^{\prime \prime}(x)}{h^{\prime}(x)^{2}}(2 h(x)+r)^{2}},
$$

and because $h^{\prime \prime}<0$, we have

$$
\left|\frac{d x}{d T}\right|<\frac{\left(\pi_{m}-2 \pi_{d}\right)(r+h(x)) h(x)}{r \frac{(2 h(x)+r)(2 h(x)+3 r)}{(h(x)+r)}} .
$$

Therefore a sufficient condition is

$$
-\left[\frac{S_{m}}{\pi_{m}}-1\right]\left(\pi_{m}-2 \pi_{d}\right) \frac{\left(h\left(x^{*}\right)+r\right)^{2}}{h\left(x^{*}\right)\left(2 h\left(x^{*}\right)+3 r\right)}+S_{d}-S_{m}>0 .
$$


Furthermore, if $r<1$,

$$
\frac{\left(h\left(x^{*}\right)+r\right)^{2}}{h\left(x^{*}\right)\left(2 h\left(x^{*}\right)+3 r\right)}<1,
$$

and we therefore obtain the second sufficient condition described in Lemma 1.

\section{We Use Lemma 1 to Prove the Different Results in Proposition 2}

(a) This result is obtained using the sufficient condition in the worst-case scenario where $\pi_{d}=0$.

(b) This condition is sufficient to guarantee that

$$
\frac{S_{m}}{\pi_{m}} \frac{r}{h\left(x^{*}\right)+r}-1>0
$$

and therefore that the sufficient condition (2) above is satisfied.

(c) Under Cournot competition and linear demand, $\pi_{d}=\frac{4}{9} \pi_{m}, S_{m}=\frac{3}{2} \pi_{m}$, and $S_{d}=\frac{16}{9} \pi_{m}$. We can therefore rewrite the sufficient condition: $-\left(\frac{3}{2} \pi_{m}-\pi_{m}\right)$ $\left(\pi_{m}-2 \frac{4}{9} \pi_{m}\right)+\pi_{m}\left(\frac{16}{9} \pi_{m}-\frac{3}{2} \pi_{m}\right)$. This condition is always satisfied.

Under Bertrand competition, we need to be a bit more precise. Let

$$
a=\frac{\left(h\left(x^{*}\right)+r\right)^{2}}{h\left(x^{*}\right)\left(2 h\left(x^{*}\right)+3 r\right)}<1 .
$$

A stricter sufficient condition is

$$
-a\left[S_{m}-\pi_{m}\right]\left[\pi_{m}-2 \pi_{d}\right]+\pi_{m}\left[S_{d}-S_{m}\right]>0 .
$$

Under Bertrand competition, the duopoly profits are 0 , therefore the condition can be written $S_{d}+a \pi_{m}-(a+1) S_{m}>0$. Using the results $S_{m}=\frac{3}{2} \pi_{m}$ and $S_{d}=S_{0}=2 \pi_{m}$, we see that this condition can be rewritten $1-a>0$. Because $a<1$, this condition is satisfied.

\section{Proof of Proposition 3}

To determine the socially optimal mix of $T$ with the other instruments of patent policy, we need to calculate the social surplus and the conditions characterizing the equilibrium amount of research $x^{*}$ when the length $L$ of the patent is finite and when surplus and profits depend on the breadth. It is a small modification of the results obtained in Section II.

The expected social surplus is given by

$$
\begin{aligned}
E[S]= & \frac{2 h\left(x^{*}\right)}{2 h\left(x^{*}\right)+r}\left[\frac{S_{m}(\alpha)}{r}\left(1-e^{-r L-h\left(x^{*}\right) T}\right)\right. \\
& \left.-\frac{S_{d}(\alpha)}{r} e^{-r L}\left(1-e^{-h\left(x^{*}\right) T}\right)+\frac{S_{0}}{r} e^{-r L}\right] \\
& +\left[1-e^{-\left(r+h\left(x^{*}\right)\right) T}\right] \frac{S_{d}(\alpha)-S_{m}(\alpha)}{r} \frac{2 h\left(x^{*}\right)^{2}}{\left(2 h\left(x^{*}\right)+r\right)\left(h\left(x^{*}\right)+r\right)}-2 x^{*} .
\end{aligned}
$$

(C) The editors of the Scandinavian Journal of Economics 2010. 
We now need to determine $x^{*}(T, L, \alpha) . S_{m}, S_{d}, \pi_{m}, \pi_{d}$, and $\pi_{L}$ all depend on the parameter $\alpha$. To simplify the notations, we do not explicitly write the dependence on $\alpha$ in the following equations.

The expected profit of firm 1, given that firm 2 is investing an amount $x_{2}$, is shown by the following:

$$
\begin{aligned}
E\left[\pi_{1}\right]= & \frac{\pi_{m}}{r}\left[1-e^{-h\left(x_{2}\right) T} e^{-r L}\right] \frac{h\left(x_{1}\right)}{h\left(x_{1}\right)+h\left(x_{2}\right)+r} \\
& -\frac{\pi_{L}}{r}\left[1-e^{-h\left(x_{1}\right) T} e^{-r L}\right] \frac{h\left(x_{2}\right)}{h\left(x_{1}\right)+h\left(x_{2}\right)+r} \\
& +\frac{\pi_{d}-\pi_{L}}{r}\left[1-e^{-\left(r+h\left(x_{1}\right)\right) T}\right] \frac{h\left(x_{1}\right) h\left(x_{2}\right)}{\left(h\left(x_{1}\right)+r\right)\left(h\left(x_{1}\right)+h\left(x_{2}\right)+r\right)} \\
& +\frac{\pi_{d}-\pi_{m}}{r}\left[1-e^{-\left(r+h\left(x_{2}\right)\right) T}\right] \frac{h\left(x_{1}\right) h\left(x_{2}\right)}{\left(h\left(x_{2}\right)+r\right)\left(h\left(x_{1}\right)+h\left(x_{2}\right)+r\right)} \\
& -\frac{\pi_{d}}{r} e^{-r L}\left(1-e^{h\left(x_{1}\right) T}\right) \frac{h\left(x_{2}\right)}{h\left(x_{1}\right)+h\left(x_{2}\right)+r} \\
& -\frac{\pi_{d}}{r} e^{-r L}\left(1-e^{h\left(x_{2}\right) T}\right) \frac{h\left(x_{1}\right)}{h\left(x_{1}\right)+h\left(x_{2}\right)+r} .
\end{aligned}
$$

Using the notation $h^{*}=h\left(x^{*}\right)$, the first-order conditions in equilibrium are therefore given by

$$
\begin{aligned}
\frac{r\left(2 h^{*}+r\right)^{2}}{\left(h^{*}\right)^{\prime}}= & \pi_{m}\left(h^{*}+r\right)\left(1-e^{-r L} e^{-h^{*} T}\right)-\pi_{m} h^{*}\left(1-e^{-\left(r+h^{*}\right) T}\right) \\
& +\left(\pi_{d}-\pi_{L}\right) T e^{-\left(r+h^{*}\right) T} \frac{\left(h^{*}\right)^{2}\left(2 h^{*}+r\right)}{h^{*}+r} \\
& +\left(\pi_{d}-\pi_{L}\right)\left(1-e^{-\left(r+h^{*}\right) T}\right)\left[r \frac{h(x)(2 h(x)+r)}{(h(x)+r)^{2}}-\frac{h(x)^{2}}{h(x)+r}\right] \\
& +\pi_{d} T e^{-r L} e^{-h^{*} T} h^{*}\left(2 h^{*}+r\right)-\pi_{d} e^{-r L}\left(1-e^{-h^{*} T}\right) \\
& +\pi_{L} T e^{-r L} e^{-h^{*} T}\left(2 h^{*}+r\right) h^{*}-\pi_{L}\left(1-e^{-r L} e^{-h^{*} T}\right) h^{*}
\end{aligned}
$$

We rewrite this equation as $G\left(x^{*}\right)=K$.

The socially optimal mix is obtained by solving the following problem, where $E(S)$ and $G\left(x^{*}\right)$ were determined above:

$\max E[S(T, L, \alpha)] \quad$ subject to $T \geq 0$ and $T \leq L$ and $G\left(x^{*}\right) \geq K$ and $\alpha \geq 0$. 
We first verify that the objective function $S(T, L, \alpha)$ is concave in $(T,-L, \alpha)$ :

$$
\begin{aligned}
\frac{\partial^{2} \mathcal{L}}{\partial L^{2}}= & \frac{r 2 h\left(x^{*}\right)}{2 h\left(x^{*}\right)+r}\left[S_{0} e^{-r L}-S_{m} e^{-r L-h\left(x^{*}\right) T}-S_{d} e^{-r L}\left(1-e^{-h\left(x^{*}\right) T}\right)\right]>0, \\
\frac{\partial^{2} \mathcal{L}}{\partial T^{2}}= & \frac{2 h^{2}\left(x^{*}\right)}{2 h\left(x^{*}\right)+r} \frac{S_{m}-S_{d}}{r}\left[\left(r+h\left(x^{*}\right)\right) e^{-\left(r+h\left(x^{*}\right)\right) T}-r e^{-r L-h\left(x^{*}\right) T}\right]<0, \\
\frac{\partial^{2} \mathcal{L}}{\partial \alpha^{2}}= & \frac{2 h\left(x^{*}\right)}{2 h\left(x^{*}\right)+r} \frac{S_{m}^{\prime \prime}(\alpha)}{r} \\
& \times\left[\left(1-e^{-r L-h\left(x^{*}\right) T}\right)-\frac{h\left(x^{*}\right)}{h\left(x^{*}\right)+r}\left(1-e^{-\left(r+h\left(x^{*}\right) T\right)}\right]<0 .\right.
\end{aligned}
$$

We can now write the Lagrangian of this problem:

$$
\mathcal{L}=E(S)+\lambda\left(K-G\left(x^{*}\right)\right)+\mu(-T)+\nu(T-L)+\gamma(-\alpha),
$$

with $\lambda \leq 0, \mu \leq 0, \nu \leq 0$, and $\gamma \leq 0$.

We want to examine under what conditions $T^{*}=0$ cannot be a solution. A set of necessary conditions for $T^{*}=0$ to be an equilibrium is as follows:

$$
\begin{aligned}
& \frac{\partial \mathcal{L}}{\partial T}\left(T^{*}=0\right) \leq 0, \\
& \frac{\partial \mathcal{L}}{\partial L}\left(T^{*}=0\right) \leq 0, \\
& \frac{\partial \mathcal{L}}{\partial \alpha}\left(T^{*}=0\right) \leq 0 .
\end{aligned}
$$

Therefore a set of sufficient conditions such that $T^{*}=0$ cannot be a solution is the following:
(a) $\frac{\partial \mathcal{L}}{\partial T}\left(T^{*}=0\right)>0$
(b) $\frac{\partial \mathcal{L}}{\partial L}\left(T^{*}=0\right) \leq 0$,
(c) $\frac{\partial \mathcal{L}}{\partial \alpha}\left(T^{*}=0\right) \leq 0$.

We first derive condition (a) using the fact that $\nu=0$ by complementary slackness:

$$
\begin{aligned}
\frac{\partial \mathcal{L}}{\partial T}(T=0)= & \frac{2\left(h^{*}\right)^{2}}{2 h^{*}+r}\left(1-e^{-r L}\right)\left(\frac{S_{d}-S_{m}}{r}\right) \\
& -\lambda\left[-\left(\pi_{m}+\pi_{L}\right)\left(h^{*}+r\right) h^{*}\left(1-e^{-r L}\right)\right. \\
& \left.+2 \pi_{d}\left(h^{*}+r\right) h^{*}\left(1-e^{-r L}\right)\right]-\mu \geq 0 .
\end{aligned}
$$

Furthermore, $\mu \leq 0$, so we can re-express condition (a) as follows:

$$
\begin{aligned}
\frac{\partial \mathcal{L}}{\partial T}(T=0)= & \frac{2\left(h^{*}\right)^{2}}{2 h^{*}+r}\left(\frac{S_{d}-S_{m}}{r}\right) \\
& -\lambda\left[-\left(\pi_{m}+\pi_{L}\right)\left(h^{*}+r\right) h^{*}+2 \pi_{d}\left(h^{*}+r\right) h^{*}\right]>0 .
\end{aligned}
$$

(C) The editors of the Scandinavian Journal of Economics 2010. 
We then derive condition (b) as:

$$
\begin{aligned}
\frac{\partial \mathcal{L}}{\partial L}\left(T^{*}=0, L^{*}\right)= & \frac{2 h^{*}}{2 h^{*}+r} e^{-r L}\left(\frac{S_{m}-S_{0}}{r}\right) \\
& -\lambda\left[\pi_{m}\left(h^{*}+r\right) r e^{-r L}+\pi_{L} h^{*} r e^{-r L}\right] \leq 0 .
\end{aligned}
$$

Finally, condition (c) is given by

$$
\begin{aligned}
\frac{\partial \mathcal{L}}{\partial \alpha}(T=0)= & \frac{S_{m}^{\prime}(\alpha)}{r} \frac{2\left(h^{*}\right)}{2 h^{*}+r}\left(1-e^{-r L}\right) \\
& -\lambda\left[\pi_{m}^{\prime}(\alpha)\left(h^{*}+r\right)\left(1-e^{-r L}\right)-\pi_{L}^{\prime}(\alpha) h^{*}\left(1-e^{-r L}\right)\right] \leq 0 .
\end{aligned}
$$

We can re-express condition (b) as

$$
-\lambda\left[\pi_{m}\left(h^{*}+r\right) r+\pi_{L} h^{*} r\right] \leq \frac{2 h^{*}}{2 h^{*}+r}\left(\frac{S_{0}-S_{m}}{r}\right) .
$$

Therefore a sufficient condition for (b) is

$$
-\lambda \leq \frac{2 h^{*}}{2 h^{*}+r}\left(\frac{S_{0}-S_{m}}{r}\right) \frac{1}{\left(\pi_{m}+\pi_{L}\right)\left(h^{*}+r\right) r} .
$$

Using this result in equation (A3), we obtain the following sufficient condition:

$$
\begin{aligned}
& \frac{2\left(h^{*}\right)^{2}}{2 h^{*}+r}\left(\frac{S_{d}-S_{m}}{r}\right) \\
& \quad+\frac{2 h^{*}}{2 h^{*}+r}\left(\frac{S_{0}-S_{m}}{r}\right) \frac{-\left(\pi_{m}+\pi_{L}\right)\left(h^{*}+r\right) h^{*}+2 \pi_{d}\left(h^{*}+r\right) h^{*}}{\left(\pi_{m}+\pi_{L}\right)\left(h^{*}+r\right) r}>0 .
\end{aligned}
$$

This can be re-expressed as the first condition in Proposition 3:

$$
\frac{S_{d}-S_{m}}{0.5\left(\pi_{m}+\pi_{L}\right)-\pi_{d}}>\frac{S_{0}-S_{m}}{0.5\left(\pi_{m}+\pi_{L}\right)} .
$$

We do the same type of derivation for the other condition. Condition (c) can be reexpressed:

$$
-\lambda \leq-\frac{2 h^{*}}{2 h^{*}+r}\left(\frac{S_{m}^{\prime}(\alpha)}{r}\right) \frac{1}{\left(\pi_{m}^{\prime}(\alpha)-\pi_{L}^{\prime *}+r\right) r} .
$$

Using this result in equation (A3) above, we obtain the second condition specified in Proposition 3:

$$
\frac{S_{d}-S_{m}}{\pi_{m}+\pi_{L}-2 \pi_{d}}>-\frac{S_{m}^{\prime}(\alpha)}{\pi_{m}^{\prime}(\alpha)-\pi_{L}^{\prime}(\alpha)} .
$$

\section{Proof of Corollary 1}

(a) As we saw in the proof of Proposition 2, with linear demand and Cournot competition, $\pi_{d}=\frac{4}{9} \pi_{m}, S_{m}=\frac{3}{2} \pi_{m}$, and $S_{d}=\frac{16}{9} \pi_{m}$. Furthermore, we define $k$ such that $0.5\left(\pi_{m}+\pi_{L}\right)=k \pi_{m}$. We of course have $k<1$.

Given these values, condition (1) is equivalent to $\left(\frac{16}{9}-\frac{3}{2}\right) k \geq\left(2-\frac{3}{2}\right)\left(k-\frac{4}{9}\right)$, which is equivalent to $k<1$. The condition is therefore satisfied. 
For result (b) we consider Bertrand competition. Under Bertrand competition, $S_{d}=S_{0}$ and $\pi_{d}=0$, so the two instruments are equivalent. We examine what happens for a small departure from perfect Cournot competition. We suppose there is, for example, a small rigidity in prices $\delta$.

We use Taylor expansions of the surplus and profits:

$$
S_{d}(\delta)=S_{d}(0)+S_{d}^{\prime}(0) \delta+\circ(\delta) .
$$

Because surplus is maximal at Bertrand prices, $S_{d}^{\prime}(0)=0$. We do a similar expansion for profits, using the fact $\pi_{d}=0$ to rewrite the condition as follows:

$$
\frac{S_{0}+\circ(\delta)-S_{m}}{S_{0}-S_{m}} \geq \frac{\pi_{m}+\pi_{L}-2 \pi_{d}^{\prime}(0) \delta-2 \circ(\delta)}{\pi_{m}+\pi_{L}} .
$$

Because $\pi_{d}^{\prime}(0)>0$, irrespective of the nature of the imperfection, the condition will be satisfied at the limit.

\section{Proof of Corollary 2}

We assume that firm 1 innovates first. Thus $\theta_{1}=\bar{\theta}+\widehat{\theta}$ and $\theta_{2}=\bar{\theta}+\alpha \widehat{\theta}$. After firms invent, prices are given by $p_{1}=t+\frac{1}{3}(1-\alpha) \widehat{\theta}$ and $p_{2}=t-\frac{1}{3}(1-\alpha) \widehat{\theta}$. The consumer who is indifferent between the two products is situated at $x=\frac{1}{2}+\frac{1}{6} t(1-\alpha) \widehat{\theta}$.

We can now calculate the different profit and welfare functions: $\pi_{m}=\left(t+\frac{1}{3}(1-\alpha) \widehat{\theta}\right) x, \pi_{L}=\left(t+\frac{1}{3}(1-\alpha) \widehat{\theta}\right)(1-x)$, and $\pi_{d}=t / 2$. Furthermore, $S_{m}=\theta_{1} x+\theta_{2}(1-x)-\frac{1}{2} t x^{2}-\frac{1}{2} t(1-x)^{2}$ and $S_{d}=\bar{\theta}+\widehat{\theta}-\frac{1}{4} t$. We also need to calculate the derivatives:

$$
\pi_{m}^{\prime}(\alpha)=-\frac{2}{3} \widehat{\theta}\left[\frac{1}{2}+\frac{1}{6 t}(1-\alpha) \widehat{\theta}\right], \quad \pi_{L}^{\prime}(\alpha)=\frac{1}{9} t(1-\alpha) \widehat{\theta}^{2},
$$

and

$$
S_{m}^{\prime}(\alpha)=-\frac{5}{18 t}(1-\alpha) \widehat{\theta}^{2}+\frac{\widehat{\theta}}{2}
$$

Condition (2) can then be re-expressed:

$$
3\left[\frac{1}{2}-\frac{5}{36 t}(1-\alpha) \widehat{\theta}\right]>3 \frac{\frac{1}{2}-(5 / 18 t)(1-\alpha) \widehat{\theta}}{1+(5 / 9 t)(1-\alpha) \widehat{\theta}} .
$$

This condition is satisfied for all values of the parameters.

\section{Proof of Corollary 3}

In this situation, $\pi_{m}=\frac{1}{9}[(2-\alpha) d]^{2}, \pi_{L}=\frac{1}{9}[(2 \alpha-1) d]^{2}$, and $\pi_{d}=\frac{1}{9} d^{2}$. In terms of welfare,

$$
S_{m}=\frac{4}{9}\left[\frac{1+\alpha}{2} d\right]^{2}+\frac{(1-\alpha)^{2} d^{2}}{2} \text { and } S_{d}=\frac{4}{9} d^{2} .
$$

We also need to calculate the derivatives: $\pi_{m}^{\prime}(\alpha)=-d \frac{2}{9}[(2-\alpha) d], \pi_{L}^{\prime}(\alpha)=$ $d \frac{4}{9}[(2 \alpha-1) d]$, and $S_{m}^{\prime}(\alpha)=d \frac{1}{9}[-7 d+11 \alpha d]$.

(C) The editors of the Scandinavian Journal of Economics 2010. 
Condition (2) can then be re-expressed:

$$
\frac{\frac{5}{2}-\alpha-\frac{3}{2} \alpha^{2}}{3-8 \alpha+5 \alpha^{2}}>\frac{-7+11 \alpha}{6 \alpha}
$$

This condition will always be satisfied.

\section{Proof of Proposition 4}

At the date of invention, the expected profits of an inventor choosing menu $(T, L)$ and facing a competitor of type $\lambda$ is expressed as follows:

$$
\begin{aligned}
E[\pi]= & \int_{0}^{L} e^{-r t} \pi_{m} d t \int_{T}^{+\infty} \lambda e^{-\lambda t_{2}} d t_{2} \\
& +\int_{0}^{T}\left[\int_{0}^{t_{2}} e^{-r t} \pi_{m} d t+\int_{t_{2}}^{L} e^{-r t} \pi_{d} d t\right] \lambda e^{-\lambda t_{2}} d t_{2} .
\end{aligned}
$$

Simplifying and factorizing, we find:

$$
\begin{aligned}
E[\pi]= & \frac{\pi_{m}}{r} e^{-\lambda T}\left[1-e^{-r L}\right]+\left[\frac{\pi_{m}}{r}-\frac{\pi_{d}}{r} e^{-r L}\right]\left[1-e^{-\lambda T}\right] \\
& +\frac{\lambda}{\lambda+r}\left[\frac{\pi_{d}}{r}-\frac{\pi_{m}}{r}\right]\left[1-e^{-(\lambda+r) T}\right] .
\end{aligned}
$$

We find that

$$
\frac{\partial \pi}{\partial T \partial \lambda}=\left[\frac{\pi_{m}}{r}-\frac{\pi_{d}}{r}\right]\left[e^{-\lambda T-r L}-e^{-(\lambda+r) T}\right][1-\lambda T] .
$$

So if $\lambda T<1,(\partial \pi / \partial T \partial \lambda)<0$. Furthermore,

$$
\frac{\partial \pi}{\partial L \partial \lambda}=\left[\frac{\pi_{d}}{r}-\frac{\pi_{m}}{r}\right] e^{-\lambda T} e^{-r L} r<0 .
$$

So under certain conditions $(\lambda T<1)$, single crossing properties are satisfied, and menus $(T, L)$ can be used to sort between more or less efficient inventors.

\section{References}

Cohen, L., and Ishii, J. (2005), Competition, Innovation and Racing for Priority at the US Patent and Trademark Office, American Law and Economics Association Annual Meetings.

Cornelli, F., and Schankerman, M. (1999), Patent Renewals and R\&D Incentives, Rand Journal of Economics 30, 197-213.

Denicolo, V. (1996), Patent Races and Optimal Patent Breadth and Length, Journal of Industrial Economics 44, 249-265.

Denicolo, V., and Franzoni, L. (2010), On the Winner-Take-All Principle in Innovation Races, forthcoming in Journal of the European Economic Association.

Gallini, N. (1992), Patent Policy and Costly Imitation, Rand Journal of Economics 23, 52-63.

Harhoff, D., Narin, F., Scherer, F., and Vopel, K. (1999), Citation Frequency and the Value of Patented Innovation, Review of Economics and Statistics 81, 511-515.

Hopenhayn, H., and Mitchell, M. (2001), Innovation Variety and Patent Breadth, Rand Journal of Economics 32, 152-166. 
Klemperer, P. (1990), How Broad Should the Scope of Patent Protection Be?, Rand Journal of Economics 21, 113-130.

La Manna, M., Macleod, R., and de Meza, D. (1989), The Case for Permissive Patents, European Economic Review 33, 1427-1443.

Lemley, M. (2007), Should Patent Infringement Require Proof of Copying?, Michigan Law Review 105, 1525-1536.

Loury, G. (1979), Market Structure and Innovation, Quarterly Journal of Economics 93, 395-410.

Maurer, S., and Scotchmer, S. (2002), The Independent Invention Defence in Intellectual Property, Economica 69, 535-547.

Moldavanu, B., and Sela, A. (2001), The Optimal Allocation of Prizes in Contests, American Economic Review 91, 542-558.

Moser, P. (2005), How Do Patent Laws Influence Innovation? Evidence from Nineteenthcentury World's Fairs, American Economic Review 95, 1215-1236.

Nordhaus, P. (1972), The Optimal Life of a Patent: A Reply, American Economic Review $62,428-431$.

Scotchmer, S. (1999), On the Optimality of the Patent Renewal System, Rand Journal of Economics 30, 181-196.

Scotchmer, S. (2004), Innovation and Incentives, MIT Press, Cambridge, MA.

Shapiro, C. (2006), Prior User Rights, American Economic Review Papers and Proceedings 96, 92-96.

Szymanski, S., and Valetti, T. (2005), Incentive Effects of Second Prizes, European Journal of Political Economy 21, 467-481.

First version submitted February 2009;

final version received September 2009. 